\title{
Associations between bovine coronavirus and bovine respiratory syncytial virus infections and animal performance in Swedish dairy herds
}

\author{
F. Beaudeau, ${ }^{*} \dagger \ddagger^{1}$ A. Ohlson, $\ddagger$ and U. Emanuelson $\ddagger$ \\ *Ecole Nationale Vétérinaire de Nantes, UMR 1300 Bio-agression, Epidémiologie et Analyse de Risque, F-44307, Nantes, France \\ †INRA, UMR 1300 Bio-agression, Epidémiologie et Analyse de Risque, F-44307, Nantes, France \\ łDepartment of Clinical Sciences, Division of Ruminant Medicine and Epidemiology, Swedish University of Agricultural Sciences, SE-750 07, \\ Uppsala, Sweden
}

\section{ABSTRACT}

To assess the economic impact of bovine coronavirus (BCV) and bovine respiratory syncytial virus (BRSV) infections, accurate estimates of their associated effects on animal performance are needed. This study aimed to quantify the variation in individual test-day milk yield and somatic cell count, risk of reproductive failure after first service of dairy cows, and risk of death of calves and heifers according to the BCV and BRSV status of the herd. Three types of status were defined for BCV and BRSV infections, based on 1) the dynamics over a 7-mo period of BCV- and BRSV-specific antibody levels in pooled milk of primiparous cows; 2) the possible occurrence of presumably BCV- and BRSV-related clinical outbreaks; and 3) the combination of both pieces of information. A total of 36,184 test days, 2,716 cows with a first service, and 4,104 calves and heifers in 65 Swedish herds were included in the analyses. Animal performance associated with BCV and BRSV infections was quantified using hierarchical mixed generalized and survival models, after adjustment for covariates known to influence the performance under study. A significant reduction in milk yield was observed for cows in presumably BRSV recently infected herds, as well as in herds having a presumably BRSV-related clinical outbreak (of 0.57 and $0.91 \mathrm{~kg} / \mathrm{d}$, respectively), compared with cows in presumably infection-free herds. There was also a significant increase in somatic cell count (of 12,000 cells $/ \mathrm{mL}$ ) for cows located in herds with a BRSV outbreak. The risk of failure after first service, as well as the risk of death in calf and heifer, was numerically higher in BRSV-infected herds, although this was not statistically significant. In contrast, BCV infection herd status, as defined in the present study, was not significantly associated with any production losses in

Received June 22, 2009.

Accepted December 2, 2009.

${ }^{1}$ Corresponding author: beaudeau@vet-nantes.fr animals from infected herds compared with those in infection-free herds.

Key words: dairy cattle, animal performance, bovine coronavirus, bovine respiratory syncytial virus

\section{INTRODUCTION}

Bovine coronavirus (BCV) and bovine respiratory syncytial virus (BRSV) are two viruses with worldwide distribution that are frequently involved in the respiratory and enteric disease complexes of cattle (Clark, 1993; Valarcher and Taylor, 2007). Bovine coronavirus has been described to be involved in winter dysentery in adults (Saif, 1990; Alenius et al., 1991), calf diarrhea (Stair et al., 1972), and in respiratory disease of young stock (McNulty et al., 1984). Bovine respiratory syncytial virus is recognized as one of the most important causes of respiratory tract disease in beef and dairy cattle, especially in young animals (Stott et al., 1980; Verhoeff et al., 1984; Elvander, 1996).

These infections are widespread in dairy cattle. Among 113 dairy herds in the Ithaca area (New York, NY), a $33 \%$ incidence of winter dysentery was recorded over a 9-mo period (White et al., 1989). Bulk tank milk data, reflecting the antibody status of lactating cows, also showed very high nationwide prevalences of BCV (89.2 to 100\%; Paton et al., 1998; Tråvén et al., 1999) and BRSV infections (70 to 100\%; Elvander, 1996; Paton et al., 1998) in the UK and Sweden. The use of a BRSV vaccine is considered to have a minimal effect on antibody levels, as its implementation was rare in UK (Paton et al., 1998) and not used at all in Sweden. Furthermore, there is no BCV vaccination program in Sweden, and none was mentioned in Paton et al. (1998). Moreover, a high BCV and BRSV infection burden and spread in calves has been recently demonstrated in the southwestern part of Sweden (Hägglund et al., 2006). Measures to control the spread of these infections may be warranted, because infectious diseases are likely to have detrimental effects on the animals and their productivity. However, information on the production 
effects associated with these infections on a dairy farm remains scarce, and an assessment of production effects at the farm level might contribute to support decisionmaking for control.

Practical experiences of farmers indicate that the losses associated with these infections may be substantial because of reduced productivity. Increased risk of mortality and premature culling, reduced growth, fertility, and milk production in first lactation associated with bovine respiratory and enteric disease in dairy calves and heifers have been quantified in the literature (Waltner-Toews et al., 1986; Curtis et al., 1988, 1989; Warnick et al., 1994, 1997; Virtala et al., 1996). However, these studies did not focus specifically on BCV or BRSV infections or on adult cows, which constitute the bulk of the production animals in a dairy herd.

For BCV infection specifically, mortality of calves in some case herds with acute outbreaks has been described (Reynolds et al., 1986), and a decrease in milk yield in relation to an extended decrease in appetite was also reported in both experimental (Tråven et al., 2001) and field (Saif et al., 1988) studies about winter dysentery (associated with BCV) in lactating cows. Some severe decreases in milk yield associated with a BRSV outbreak have been described by Odegaard and Krogsrud (1977) and Harrison and Pursell (1985). Only one study (Norström et al., 2001) has quantified this loss, with accounting for other factors affecting milk yield: the daily loss was estimated to be small $(0.7 \mathrm{~kg}$ per cow and day in the week following a BRSV outbreak, compared with the period $>1$ wk before the outbreak), but the authors stated that it was probably underestimated.

To our knowledge, no previous investigations have focused on the possible variation in performance of cows and young stock in commercial dairy herds with different statuses of BRSV and BCV infections. Therefore, the aim of the present study was to quantify, in a sample of Swedish dairy farms, the possible variation in milk yield, SCC, and reproductive performance of cows, and in the risk of death of young stock, according to the status toward BCV and BRSV infections of the herds. Our assumption was that a recent or current BCV or BRSV infection could be associated with a reduction in individual milk yield, higher SCC, and reduction in reproductive performance (in relation to fever and loss of appetite) of cows and a higher risk of death of young stock.

\section{MATERIALS AND METHODS}

\section{Herds and Animals}

Data came from dairy herds located in the Uppland County (central-eastern Sweden). Herds were members of the local livestock association (Svenska Husdjur) and enrolled in the National Animal Disease Recording System (Emanuelson, 1988) as well as in the Swedish Official Milk Recording Scheme (Olsson et al., 2001). These herds participated in a specific study aiming at investigating the dynamics of BRSV and BCV infections [A. Ohlson, E. Emanuelson, M. Tråvén, and S. Alenius (both of Department of Clinical Sciences, Swedish University of Agricultural Sciences, Uppsala, Sweden); unpublished data]. During this study, periodic testing at 4 sampling times (fall 2006, spring 2007, fall 2007, and spring 2008) was performed to measure the level of BCV- and BRSV-specific antibodies in milk. In each herd, information on individual milk production, SCC, and reproductive events (calvings, AI, and pregnancy checks), as well as entrance dates and exit dates and reasons for exit was available for all animals present at any point in time.

\section{Health Data Collection}

In each herd, at each sampling time, the level of BCV- and BRSV-specific antibodies was assessed from pooled milk samples of 5 home-bred primiparous cows. Testing of such samples by ELISA has recently been recognized as a suitable method to detect the putative presence of cows with antibodies to BCV or BRSV in dairy herds: there was good agreement between results of individual samples and the results of pooled samples (Ohlson et al., 2009). Such a strategy has been successfully used to determine BVDV herd status on a large scale (Lindberg and Alenius, 1999). Compared with assessment of bulk tank milk, a more immediate assessment of herd status was achieved by sampling young cows, as the antibodies may remain detectable for years without reinfection. The sampling was performed by veterinarians and technicians. Ten-milliliter test tubes containing $1.5 \mathrm{mg}$ of the preservative agent Bronopol (2-bromo-2-nitropropane-1.3-diol, Steins Laboratory, Jönköping, Sweden) were used. The samples were not diluted or centrifuged and were stored at $-20^{\circ} \mathrm{C}$ until analysis. The milk samples were analyzed for presence of immunoglobulin $\mathrm{G}$ antibodies to BCV (Alenius et al., 1991) and BRSV (Elvander et al., 1995) by commercially available indirect ELISA (Svanova Biotech, Uppsala, Sweden). The same batch was used for all analyses. The optical density (OD) at $450 \mathrm{~nm}$ was corrected by subtraction of the negative control antigen OD. To adjust for day-to-day variations, the percentage positivity (PP) was calculated as follows: (corrected $\mathrm{OD} /$ positive control corrected OD) $\times 100$. Cut-off was set to $\mathrm{PP}$ equal to 20 , corresponding to a corrected OD of 0.20 , which is the cut-off recommended by the manufacturer for individual milk samples. Using serum, 
Table 1. Distribution of herd-periods ${ }^{1}$ according to their infection status with respect to bovine respiratory syncytial virus (BRSV) and bovine coronavirus $(\mathrm{BCV})^{2}$

\begin{tabular}{|c|c|c|c|c|c|c|}
\hline \multirow{3}{*}{\multicolumn{2}{|c|}{ BRSV infection status ${ }^{1}$}} & \multicolumn{5}{|c|}{ BCV infection status ${ }^{1}$} \\
\hline & & \multicolumn{2}{|c|}{ RI } & \multicolumn{2}{|c|}{ PSI } & \multirow[b]{2}{*}{ FREI } \\
\hline & & RI-Y & RI-N & PSI-Y & PSI-N & \\
\hline \multirow[t]{2}{*}{ RI } & RI-Y & 1 & 0 & 0 & 3 & 1 \\
\hline & RI-N & 4 & 1 & 1 & 5 & 1 \\
\hline \multirow[t]{2}{*}{ PSI } & PSI-Y & 2 & 0 & 0 & 0 & 1 \\
\hline & PSI-N & 9 & 3 & 8 & 26 & 17 \\
\hline FREE & & 1 & 3 & 2 & 3 & 9 \\
\hline
\end{tabular}

${ }^{1}$ See main text for definition.

${ }^{2} \mathrm{RI}=$ presumably recently infected; RI-Y = presumably recently infected with an outbreak; RI-N = presumably recently infected without any outbreak; PSI = presumably past steadily infected; PSI-Y = presumably past steadily infected with an outbreak; PSI-N = presumably past steadily infected without any outbreak; $\mathrm{FREE}=$ presumably free of infection

the sensitivity and specificity of the BCV assay, relative to a virus neutralization test, were estimated to be 84.6 and $100 \%$, respectively (91 sera from 9 Swedish dairy herds; Alenius et al., 1991). Corresponding values for the BRSV assay were 94.0 and $100 \%$, respectively, relative to an established ELISA in use at the Central Veterinary Laboratory (Weybridge, UK; 157 sera from Swedish and English herds; Elvander et al., 1995). The 2 assays have been recognized to work equally well in milk and serum [S. Alenius (Department of Clinical Sciences, Swedish University of Agricultural Sciences, Uppsala, Sweden), personal communication; Elvander et al., 1995]. The same PP cut-off of 20 was applied to pooled milk samples, because Ohlson et al. (2009) found a good agreement (97 and 94\%) between results of individual and pooled samples for BCV and BRSV assays, respectively. Therefore, a herd was considered as positive if the PP value was $\geq 20$, and negative otherwise.

At the end of each winter season (April 2007 and 2008), farmers completed a questionnaire in which they were asked to declare the occurrence of any clinical signs presumably related to BCV or BRSV outbreaks, defined as diarrhea or respiratory signs affecting at least $25 \%$ of the dairy cows present within $1 \mathrm{wk}$. In case of occurrence, the farmers had, through not mutually exclusive closed questions, 1) to describe the observed signs (diarrhea, cough) and 2) to score their severity (from $0=$ no to $3=$ severe).

\section{BRSV and BCV Infection Herd Status}

Two periods-at-risk for a herd to get an infection were determined for each herd: fall 2006 to spring 2007 (period A), and fall 2007 to spring 2008 (period B). The BRSV and BCV infection herd statuses were then defined on a period-at-risk basis. Therefore, in each herd that was sampled 4 times, 2 periods-at-risk were considered.

For each herd-period-at-risk, 3 types (I, II, III) of herd status were defined in the same way for BCV and BRSV infections. These types were based on 1) the dynamics of BCV- and BRSV-specific antibody levels (type I); 2) the possible occurrence of a presumably BCV- or BRSV-related clinical outbreak (type II); and 3) the combination of both pieces of information (type III).

The type I herd status had 4 classes for BCV and BRSV infections separately. Herds that tested negative in fall of year $n$ and positive in spring of year $n+$ 1 were presumed to be recently infected $(\mathbf{R I})$; those that tested positive twice consecutively were presumed to be past steadily infected (PSI); those that tested positive and then tested negative were presumed to be past infected-recently recovered (PIRR); those that tested negative twice consecutively were presumed to be noninfected (NI), at least for the last 2 yr. Because our objective was to assess the production effects associated with a presumably steady or recent infection, PIRR and NI herd-periods were considered together in one group taken as the reference class (FREE; Table $1)$.

The type II herd-status had 2 classes separately for BRSV and BCV infections: absence $(\mathbf{O}-\mathbf{N})$ versus presence $(\mathbf{O}-\mathbf{Y})$ of a presumably related clinical outbreak within the herd-period-at-risk. The information about the occurrence of clinical signs was used to define presumably BCV-related outbreaks and presumably BRSV-related outbreaks, according to classification rules, relying on the type of observed signs (diarrhea vs. cough) and their scoring (Figure 1). When farmers scored the same grade for cough and diarrhea, the concerned outbreaks were defined to be presumably $\mathrm{BCV}$ related, because BRSV infection is mainly associ- 


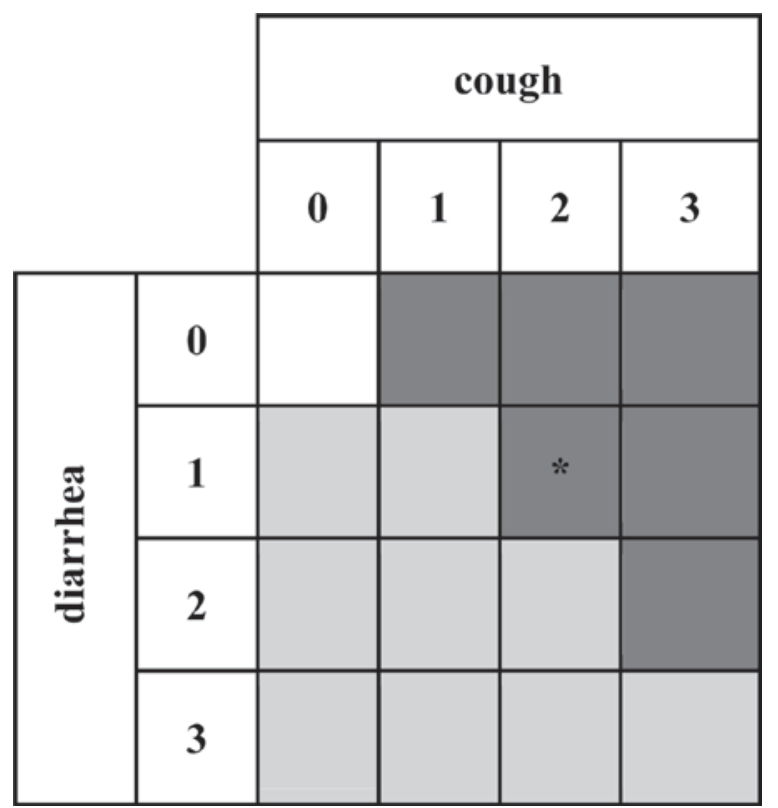

Figure 1. Classification of presumably bovine respiratory syncytial virus (BRSV)-related outbreaks (dark gray) and bovine coronavirus (BCV)-related outbreaks (light gray) according to the type of observed signs (diarrhea and cough) and their severity scoring (0 to 3). One herd $(*)$ being antibody negative to BRSV and positive to BCV in the follow-up milk sample was considered as having a BCV outbreak.

ated with respiratory signs, whereas $\mathrm{BCV}$ infection can cause both respiratory and enteric signs.

The type III herd-status had 5 classes (Table 1): RI herd without any declared outbreak within the herdperiod-at-risk (RI-N); RI herd with a declared outbreak within the herd-period-at-risk (RI-Y); PSI herd without any declared outbreak within the herd-periodat-risk (PSI-N); PSI herd with a declared outbreak within the herd-period-at-risk (PSI-Y); and FREE herds. As expected, no FREE herds (defined based on the dynamics of BCV- and BRSV-specific antibody levels) experienced a declared outbreak.

\section{Modeling}

General Principle. The aim of this study was to assess effects associated with presumably recent or steady $\mathrm{BCV}$ and BRSV infections. Because our assumptions were that milk yield, SCC, reproductive failure after first AI, and young stock mortality may be affected by both infections, all models were run with both BRSV and BCV infection herd statuses introduced as covariates. Then, for BRSV infection, the provided estimates were adjusted for the possible effect of BCV infection and vice versa. For each outcome variable, 3 different analyses were performed: model I, model II, model III including type I, type II, and type III statuses defined above as covariates, respectively.

The infection statuses were defined at the herd level, whereas the performance of cows (milk yield, SCC, reproduction) and of young stock (mortality) was considered at the individual level. Because the time of putative infection within a given period-at-risk was not known, we considered that all individual performances occurring within the period-at-risk were potentially affected. Therefore, all performances occurring between the starting and ending dates of the period-at-risk were taken into account in the analyses. Starting and ending dates were defined to be October 1 , year $n$, and April 30 , year $n+1$, because the fall milk samples were collected in September and the spring samples in May.

The corresponding herd statuses were then assigned to each individual performance of each animal, depending on the herd to which it belonged. Because the individual performances were clustered within cow (testday milk yield, test-day SCC), and the animals (cows, young stock) were clustered within herd, hierarchical mixed models considering herd and cow as random effects were performed.

Association with Milk Yield and SCC. The outcome variables were the individual monthly testday milk yield (TDMY) and SCC (TDSCC) of cows. Only test-days occurring between October 1, 2006, and April 30, 2007, or October 1, 2007, and April 30, 2008 were considered for analyses. The associations between herd-status and TDMY or TDSCC (after logarithmic transformation) were assessed using mixed linear models, after adjustment for herd, cow, DIM, parity, breed, and season. The models (MIXED procedure, SAS Institute Inc., Cary, NC) were as follows:

$$
\begin{aligned}
\mathrm{Y}=\mathrm{m} & +\mathrm{BRSV}_{i}+\mathrm{BCV}_{j}+\mathrm{DIM}_{k}+\mathrm{LN}_{l}+\mathrm{BR}_{m} \\
& +\mathrm{SEAS}_{n}+\mathrm{H}_{o}+\mathrm{COW}_{p}+\mathrm{e}_{i j k l m n o p},
\end{aligned}
$$

where $\mathrm{Y}$ is the TDMY or the log-transformed TD$\mathrm{SCC} ; \mathrm{m}$ is the overall mean; $\mathrm{BRSV}_{i}$ is the fixed effect of BRSV-related herd-status $i$ (3 classes for type I, 2 classes for type II, 5 classes for type III); $\mathrm{BCV}_{j}$ is the fixed effect of BCV-related herd-status $j$ ( 3 classes for type I, 2 classes for type II, 5 classes for type III); $\mathrm{DIM}_{k}$ is the fixed effect of class $k$ of DIM (13 classes); $\mathrm{LN}_{l}$ is the fixed effect of class $l$ of lactation number (5 classes: $1,2,3,4$, and $\geq 5$ ); $\mathrm{BR}_{m}$ is the fixed effect of class $m$ of breed (3 classes: Swedish Red, Swedish Holstein, others); $\mathrm{SEAS}_{n}$ is the fixed effect of class $n$ of season (2 classes: October to December, January to April); $\mathrm{H}_{o}$ is the random effect of herd $o$ (65 herds); $\mathrm{COW}_{p}$ is the random effect of cow $p$ within herd $o$; and 
$\mathrm{e}_{i j k l m n o p}$ is the residual. For each class variable, dummy coding was done setting the reference level to zero: each estimate thus measures the effect of each nonreference level compared with the reference level. The cow taken as reference was in a FREE herd when considering type I and III statuses, and in an O-N herd for type II status. To account for correlations between test days within cow, a compound symmetry variance matrix was used. A first-order autoregressive variance matrix was initially attempted for TDMY because other research (Gröhn et al., 1999) has indicated that it may be the most appropriate, but the models did not converge.

Association with Reproductive Performance. The reproductive performance was assessed by the outcome "reproductive failure versus success." A success was defined as a new calving occurring after the first AI after calving; that is, which was not followed by any other subsequent AI within the lactation and with the calving occurring within a delay compatible with a gestation length $(<300 \mathrm{~d})$. Cows with no information on subsequent calving but a successful pregnancy check after first AI and no subsequent recorded AI were considered as experiencing a success. Other situations were considered as failure. However, cows with no subsequent events (AI, pregnancy checks, culling, calving) recorded after first AI or culled within $200 \mathrm{~d}$ after first AI were considered as noninformative, because their outcomes could not be reliably defined; they were then excluded from the analyses. Preliminary investigations showed that the proportions of noninformative animals did not differ statistically $(P>0.05)$ according to the BCV and BRSV infection status of the herd to which they belonged. Only first AI occurring between October 1, 2006, and April 30, 2007, or between October 1, 2007, and April 30, 2008 were considered for analyses. The association between herd status and "calving after first service" was assessed using a mixed logistic regression model. The model (GLIMMIX macro, SAS Institute Inc.) was as follows:

$$
\begin{gathered}
\mathrm{Y}=\mathrm{m}+\mathrm{BRSV}_{i}+\mathrm{BCV}_{j}+\mathrm{C}-\mathrm{AI}_{k}+\mathrm{LN}_{l}+\mathrm{BR}_{m} \\
+\mathrm{SEAS}_{n}+\mathrm{MY}_{o}+\mathrm{EB}_{p}+\mathrm{H}_{q}+\mathrm{COW}_{r}+\mathrm{e}_{i j k l m n o p q r},
\end{gathered}
$$

where $\mathrm{Y}$ is the dependent variable (failure vs. success); $\mathrm{m}$ is the overall mean; $\mathrm{BRSV}_{i}$ is the fixed effect of BRSV-related herd status $i$ (3 classes for type I, 2 classes for type II, 5 classes for type III); $\mathrm{BCV}_{j}$ is the fixed effect of BCV-related herd status $j$ ( 3 classes for type I, 2 classes for type II, 5 classes for type III); C-AI $k$ is the fixed effect of class $k$ of calving-to-AI interval (7 classes); $\mathrm{LN}_{l}$ is the fixed effect of class $l$ of lactation number ( 5 classes: $1,2,3,4$, and $\geq 5$ ); $\mathrm{BR}_{m}$ is the fixed effect of class $m$ of breed ( 3 classes: Swedish Red, Swed- ish Holstein, others); $\mathrm{SEAS}_{n}$ is the fixed effect of class $n$ of season (2 classes: October to December, January to April); $\mathrm{MY}_{o}$ is the fixed effect of class $o$ of milk yield, expressed as the maximum of the first 3 TDMY (3 classes); $\mathrm{EB}_{p}$ is the fixed effect of class $p$ of energy balance in early lactation, estimated as the minimum of the milk protein content:fat content ratio out of the first 3 test-day records (3 classes); $\mathrm{H}_{q}$ is the random effect of herd $q$ (65 herds); $\mathrm{COW}_{r}$ is the random effect of cow $r$ within herd $q$; and $\mathrm{e}_{i j k l m n o p q r}$ is the residual. The cow taken as a reference had a success; that is, a calving or positive pregnancy check after first AI, in a FREE herd when considering type I and III statuses, and in an O-N herd for type II status. For each covariate, the logistic regression models provide adjusted odds ratios (OR). Because OR are overestimating relative risks (RR), especially when the incidence of the event under study is high, OR were converted into RR using the method developed by Beaudeau and Fourichon (1998).

Association with Young Stock Mortality. The risk of mortality in young stock was assessed using survival analysis to account for both the length of exposure to a risk of mortality that varied between animals, and censorship. Young stock fattened and sent to slaughter, sold to another herd, or temporarily out of the herd were considered as censored at their date of exit from the herd. As male calves are usually sold early in life in Swedish dairy herds, the young stock considered here were mostly female calves and heifers. Calves and heifers still alive at the end of the periodat-risk were considered as censored at its ending date (April 30, 2007 for period A; April 30, 2008 for period B). Animals born before the starting date of the periodat-risk (October 1, 2006 for period A; October 1, 2007 for period $\mathrm{B}$ ) were considered at risk of mortality in association with BRSV and BCV infections from this starting date and therefore introduced in the survival model as left-truncated individuals. Only calves aged 3 to $500 \mathrm{~d}$ old at the ending day of the period-at-risk were retained for analyses, because the risk of dying of pneumonia or diarrhea was found to be extremely low afterward (Svensson et al., 2006).

The association between herd-status and mortality was assessed using a Cox proportional-hazard model (PHREG procedure, SAS Institute Inc.). This model was based on the concept of hazard function $\lambda(t)$, where $\lambda(t)$ is the probability for an animal of dying at $t$, given that it is still alive before $t$. This hazard characterizes the relative risk of death. The hazard rate $\lambda(t)=\lambda\left[t, z_{i}(t)\right]$ is the product of a baseline function $\lambda_{0}(t)$ and of $\exp \left(z_{1} \beta\right)$, representing the vector of covariates that influences the incidence rate of death over time. The effects of these covariates can be estimated independently from the baseline hazard function with a 
procedure of semiparametric estimation, which involves the maximization of a partial likelihood. The baseline hazard function can then be unspecified.

The model considered here was as follows:

$$
\begin{aligned}
\lambda(t)=\lambda_{0}(t) & \exp \left(\mathrm{BRSV}_{i}+\mathrm{BCV}_{j}+\mathrm{LN}_{k}\right. \\
& \left.+\mathrm{SEAS}_{l}\right)+\mathrm{e}_{i j k l},
\end{aligned}
$$

where $\lambda(t)$ is the hazard function at time $t ; \lambda_{0}(t)$ is the unspecified hazard function; $\mathrm{BRSV}_{i}$ is the fixed effect of BRSV-related herd-status $i$ (3 classes for type I, 2 classes for type II, 5 classes for type III); $\mathrm{BCV}_{j}$ is the fixed effect of BCV-related herd-status $j$ (3 classes for type I, 2 classes for type II, 5 classes for type III); $\mathrm{LN}_{k}$ is the fixed effect of class $k$ of the parity of the mother (2 classes: primiparous, multiparous); $\mathrm{SEAS}_{l}$ is the fixed effect of class $l$ of season of birth (3 classes: May to August, September to November, December to April); and $\mathrm{e}_{i j k l}$ is the residual. The observations analyzed were the length of life, defined for each animal as the number of days between d 3 after birth and the mortality day, or if still alive, the last day of the period-at-risk. The assumption of proportional hazards was checked by including time-dependent covariates, defined as interactions of the 4 putative predictors described above and the logarithm of the survival time, in the Cox models and testing for significance. The assumption of proportionality was not rejected $(P>0.05)$ in any model (results not shown). To account for clustering (i.e., animals are not independent within herd), the data were fitted by using the robust sandwich estimate (Wei et al., 1989) for statistical inference (computation of robust estimates of standard errors). An adjusted relative hazard ratio (HR) was estimated for each covariate by taking the exponent of the estimates of effects. This HR measures the instantaneous hazard for a calf to die when exposed (e.g., in RI or PSI herds) versus being unexposed (e.g., in FREE herds).

\section{RESULTS}

A total of 101 herd-periods ( 55 from period A; 46 from period B) from 65 herds were considered for analysis. The different number of observations between periods was because of missing milk samples at some sampling times. The distribution of herd-periods in each BCV and BRSV herd status is shown in Table 1. The relative proportions of periods-at-risk in status RI, PSI, and FREE were 17, 65, and $18 \%$ and 24,47 , and $29 \%$ for BRSV infection and BCV infection, respectively. The proportion of periods-at-risk with an outbreak classified as BRSV related was $8 \%$, whereas this proportion was $34 \%$ for BCV related outbreaks.

A total of 36,184 test-days, 2,716 cows with a first AI within the periods-at-risk, and 4,104 calves and heifers were retained for analyses of TDMY and TDSCC, risk of failure, and risk of mortality, respectively.

\section{Effects Associated with BRSV Infection Herd Status}

The relationships between BRSV infection herd statuses and milk yield, SCC, calving after first AI and young stock mortality are displayed in Tables $2,3,4$, and 5 , respectively.

Table 2. Adjusted effects on test-day milk yield (TDMY; $\mathrm{kg} / \mathrm{d}$ ) according to herd status with respect to bovine respiratory syncytial virus (BRSV) and bovine coronavirus (BCV) infection

\begin{tabular}{lccccc}
\hline & \multicolumn{2}{c}{ BRSV } & & \multicolumn{2}{c}{ BCV } \\
\cline { 2 - 3 } \cline { 5 - 6 } Herd status $^{1}$ & TDMY & $95 \%$ CI & & TDMY & $95 \%$ CI \\
\hline Type I status (model I) & & & & \\
RI & -0.57 & $-1.05 ;-0.08$ & & 0.01 & $-0.41 ; 0.42$ \\
PSI & 0.16 & $-0.36 ; 0.68$ & & -0.13 & $-0.57 ; 0.31$ \\
FREE & Reference & - & & Reference & - \\
Type II status (model II) & & & & 0.06 & $-0.20 ; 0.32$ \\
O-Y & -0.91 & $-1.34 ;-0.49$ & & Reference & - \\
O-N & Reference & - & & 0.32 & $-0.13 ; 0.78$ \\
Type III status (model III) ${ }^{2}$ & -1.42 & $-2.11 ;-0.74$ & & -0.95 & $-1.62 ;-0.28$ \\
RI-Y & -0.58 & $-1.11 ;-0.04$ & & 0.16 & $-0.45 ; 0.76$ \\
RI-N & -0.99 & $-2.19 ; 0.21$ & & 0.05 & $-0.41 ; 0.50$ \\
PSI-Y & -0.19 & $-0.74 ; 0.36$ & & Reference & - \\
PSI-N & Reference & - & & \\
FREE & & & & &
\end{tabular}

${ }^{1} \mathrm{RI}=$ presumably recently infected; PSI $=$ presumably past steadily infected; FREE $=$ presumably free of infection; $\mathrm{O}-\mathrm{Y}=$ with an outbreak; $\mathrm{O}-\mathrm{N}=$ without any outbreak; $\mathrm{RI}-\mathrm{Y}=$ presumably recently infected with an outbreak; RI-N = presumably recently infected without any outbreak; PSI-Y = presumably past steadily infected with an outbreak; PSI-N = presumably past steadily infected without any outbreak.

${ }^{2}$ See main text for definition. 
The first, second (median), and third quartiles of observed TDMY of cows in FREE herds were 21.9, 27.8, and $34.0 \mathrm{~kg} / \mathrm{d}$, respectively. Cows in herds classified as RI had a significantly $(P<0.05)$ lower milk yield than cows in FREE herds (reduction of $0.57 \mathrm{~kg} / \mathrm{d}$; Table 2). The reduction in milk yield in cows from $\mathrm{O}-\mathrm{Y}$ herds (with a BRSV-related outbreak) was $0.91 \mathrm{~kg} / \mathrm{d}(P<$ 0.05). Cows in RI herds with an outbreak (RI-Y herds) showed a greater reduction in milk yield $(-0.84 \mathrm{~kg} / \mathrm{d}$; $P<0.05)$ compared with cows in RI herds without any declared BRSV-related outbreak (RI-N herds).

The geometric mean $(95 \% \mathrm{CI})$ of observed TDSCC of cows in FREE herds was 82,000 (7,000-1,020,000 cells/ $\mathrm{mL})$. The SCC of cows in herds classified as RI and PSI were not significantly $(P>0.05)$ different from those in cows from FREE herds $(-3,000$ and 0 cells $/ \mathrm{mL}$, respectively; Table 3$)$. However, there was a significant $(P<0.05)$ increase in SCC, corresponding to 12,000 cells $/ \mathrm{mL}$, in cows from $\mathrm{O}-\mathrm{Y}$ herds compared with cows in $\mathrm{O}-\mathrm{N}$ herds. In addition, cows in RI-Y herds had significantly increased SCC $(18,000$ cells $/ \mathrm{mL} ; P<0.05)$ compared with cows in RI-N herds.

The proportion of reproductive failure after first AI of the 410 cows located in FREE herds was $60.0 \%$. The BRSV-related statuses, regardless of their definition, were not significantly $(P>0.05)$ associated with calving rate (Table 4). However, there was a trend toward a higher risk of failure in cows from herds experiencing an outbreak (O-Y and RI-Y) compared with O-N and FREE herds.

In the population of 569 calves and heifers present in the FREE herds within the periods-at-risk, the mortality probability at $500 \mathrm{~d}$ of age was 0.032 (product-limit estimate); that is, $3.2 \%$ of the animals at risk had died at that age. The BRSV-related statuses, regardless of their definition, were not significantly $(P>0.05)$ associated with the death hazard (Table 5). However, there was a trend toward a greater risk of death in calves and heifers from infected herds. Calves and heifers in a PSI-Y herd had a significantly higher $(P<0.05)$ death hazard $(\mathrm{HR}=2.14)$ than those in a FREE herd.

\section{Effects Associated with BCV Infection Herd Status}

The relationships between $\mathrm{BCV}$ infection herd status and milk yield, SCC, calving after first AI, and young stock mortality are displayed in Tables 2, 3, 4 and 5 , respectively. The first quartile, median, and third quartile of observed TDMY of cows in FREE herds were $21.6,27.4$, and $34.0 \mathrm{~kg} / \mathrm{d}$, respectively. The BCVrelated statuses, regardless of their definition, were not significantly $(P>0.05)$ associated with TDMY (Table $2)$. Only cows in RI-N herds had a significant reduction in milk yield $(-0.95 \mathrm{~kg} / \mathrm{d} ; P<0.05)$ compared with cows in FREE herds.

The geometric mean $(95 \% \mathrm{CI})$ of observed TDSCC of cows in FREE herds was 86,000 (7,000-1,140,000 cells $/ \mathrm{mL})$. The TDSCC did not differ significantly $(P$ $>0.05$ ) between the herd statuses (Table 3 ). The proportion of failure after first AI of the 552 cows located in FREE herds was $56.3 \%$. The BCV-related statuses, regardless of their definition, were not significantly $(P$ $>0.05$ ) associated with calving rate (Table 4).

In the population of 833 calves and heifers present in the FREE herds within the periods-at-risk, the mortality probability at $500 \mathrm{~d}$ of age was 0.048 (product-limit

Table 3. Adjusted effects on test-day SCC (TDSCC; $\times 1,000$ cells $/ \mathrm{mL}$ ) according to the herd-status with respect to bovine respiratory syncytial virus (BRSV) and bovine coronavirus (BCV) infection

\begin{tabular}{|c|c|c|c|c|}
\hline \multirow[b]{2}{*}{ Herd status $^{1}$} & \multicolumn{2}{|c|}{ BRSV } & \multicolumn{2}{|c|}{$\mathrm{BCV}$} \\
\hline & TDSCC & $95 \% \mathrm{CI}$ & TDSCC & $95 \% \mathrm{CI}$ \\
\hline \multicolumn{5}{|c|}{ Type I status $\left(\right.$ model I) ${ }^{2}$} \\
\hline RI & -3 & $-18 ; 4$ & -1 & $-13 ; 10$ \\
\hline PSI & 0 & $-11 ; 17$ & 4 & $-1 ; 28$ \\
\hline FREE & Reference & - & Reference & - \\
\hline \multicolumn{5}{|c|}{ Type II status (model II $)^{2}$} \\
\hline $\mathrm{O}-\mathrm{Y}$ & 12 & $3 ; 34$ & -3 & $-19 ; 3$ \\
\hline $\mathrm{O}-\mathrm{N}$ & Reference & - & Reference & - \\
\hline \multicolumn{5}{|c|}{ Type III status (model III) ${ }^{2}$} \\
\hline RI-Y & 8 & $3 ; 52$ & 1 & $-8 ; 18$ \\
\hline RI-N & -10 & $-34 ;-15$ & -6 & $-31 ; 1$ \\
\hline PSI-Y & 6 & $-13 ; 65$ & 1 & $-12 ; 23$ \\
\hline PSI-N & 0 & $-13 ; 16$ & 3 & $-4 ; 23$ \\
\hline FREE & Reference & - & Reference & - \\
\hline
\end{tabular}

${ }^{1} \mathrm{RI}=$ presumably recently infected; PSI $=$ presumably past steadily infected; FREE $=$ presumably free of infection; $\mathrm{O}-\mathrm{Y}=$ with an outbreak; O-N = without any outbreak; RI-Y = presumably recently infected with an outbreak; RI-N = presumably recently infected without any outbreak; PSI-Y = presumably past steadily infected with an outbreak; PSI-N = presumably past steadily infected without any outbreak.

${ }^{2}$ See main text for definition. 
Table 4. Adjusted relative risk of reproductive failure after first AI according to herd status with respect to bovine respiratory syncytial virus (BRSV) and bovine coronavirus (BCV) infection

\begin{tabular}{|c|c|c|c|c|}
\hline \multirow[b]{2}{*}{ Herd status ${ }^{1}$} & \multicolumn{2}{|c|}{ BRSV } & \multicolumn{2}{|c|}{$\mathrm{BCV}$} \\
\hline & Relative risk & $95 \%$ CI & Relative risk & $95 \% \mathrm{CI}$ \\
\hline \multicolumn{5}{|c|}{ Type I status $(\text { model I })^{2}$} \\
\hline RI & 1.01 & $0.86 ; 1.21$ & 0.96 & $0.83 ; 1.11$ \\
\hline PSI & 0.96 & $0.91 ; 1.01$ & 1.04 & $0.97 ; 1.12$ \\
\hline FREE & Reference & - & Reference & - \\
\hline \multicolumn{5}{|c|}{ Type II status (model II) ${ }^{2}$} \\
\hline $\mathrm{O}-\mathrm{Y}$ & 1.16 & $0.85 ; 1.58$ & 0.93 & $0.79 ; 1.10$ \\
\hline $\mathrm{O}-\mathrm{N}$ & Reference & - & Reference & - \\
\hline \multicolumn{5}{|c|}{ Type III status (model III) ${ }^{2}$} \\
\hline RI-Y & 1.07 & $0.74 ; 1.56$ & 0.92 & $0.76 ; 1.12$ \\
\hline RI-N & 1.02 & $0.81 ; 1.31$ & 0.99 & $0.68 ; 1.43$ \\
\hline PSI-Y & 0.98 & $0.59 ; 1.67$ & 1.16 & $0.87 ; 1.56$ \\
\hline PSI-N & 0.96 & $0.91 ; 1.02$ & 1.04 & $0.96 ; 1.14$ \\
\hline FREE & Reference & - & Reference & - \\
\hline
\end{tabular}

${ }^{1} \mathrm{RI}=$ presumably recently infected; PSI $=$ presumably past steadily infected; FREE $=$ presumably free of infection; $\mathrm{O}-\mathrm{Y}=$ with an outbreak; $\mathrm{O}-\mathrm{N}=$ without any outbreak; $\mathrm{RI}-\mathrm{Y}=$ presumably recently infected with an outbreak; RI-N = presumably recently infected without any outbreak; PSI-Y = presumably past steadily infected with an outbreak; PSI-N = presumably past steadily infected without any outbreak.

${ }^{2}$ See main text for definition.

estimate); that is, $4.8 \%$ of the animals at risk had died at that age. In contrast to our assumptions, calves and heifers in presumably BCV-infected herds (O-Y, RI, and RI-Y) had a significantly lower probability of dying than the ones in O-N and FREE herds.

\section{Effects of Adjustment Variables}

The direction of estimates associated with the adjustment covariates was comparable to that described in the literature. Thus, TDMY and TDSCC were lower in lactation number $\leq 2$ than in older cows and varied with DIM in agreement with an expected lactation curve. Risk of reproductive failure was higher in cows in lactation number $\geq 3$, with a shorter calving-toAI interval, a higher milk yield, and a lower protein content:fat content ratio in early lactation. Test-day milk yield, TDSCC, and risk of reproductive failure were higher in winter (January to April) than in the period October to December. The probability of death was higher in calves and heifers born to primiparous cows.

Table 5. Adjusted hazard ratio of calf and heifer mortality according to herd status with respect to bovine respiratory syncytial virus (BRSV) and bovine coronavirus (BCV) infection

\begin{tabular}{|c|c|c|c|c|}
\hline \multirow[b]{2}{*}{ Herd-status $^{1}$} & \multicolumn{2}{|c|}{ BRSV } & \multicolumn{2}{|c|}{$\mathrm{BCV}$} \\
\hline & Hazard ratio & $95 \% \mathrm{CI}$ & Hazard ratio & $95 \% \mathrm{CI}$ \\
\hline \multicolumn{5}{|c|}{ Type I status $(\text { model I })^{2}$} \\
\hline RI & 1.42 & $0.73 ; 2.77$ & 0.50 & $0.26 ; 0.96$ \\
\hline PSI & 1.26 & $0.77 ; 2.04$ & 1.19 & $0.69 ; 2.05$ \\
\hline FREE & Reference & - & Reference & - \\
\hline \multicolumn{5}{|c|}{ Type II status (model II) ${ }^{2}$} \\
\hline $\mathrm{O}-\mathrm{Y}$ & 1.53 & $0.85 ; 2.76$ & 0.45 & $0.25 ; 0.80$ \\
\hline $\mathrm{O}-\mathrm{N}$ & Reference & - & Reference & - \\
\hline \multicolumn{5}{|c|}{ Type III status (model III) ${ }^{2}$} \\
\hline RI-Y & 1.58 & $0.63 ; 3.95$ & 0.50 & $0.25 ; 1.00$ \\
\hline RI-N & 1.19 & $0.54 ; 2.62$ & 0.39 & $0.14 ; 1.11$ \\
\hline PSI-Y & 2.14 & $1.29 ; 3.54$ & 0.59 & $0.21 ; 1.66$ \\
\hline PSI-N & 1.18 & $0.77 ; 1.80$ & 1.37 & $0.79 ; 2.39$ \\
\hline FREE & Reference & - & Reference & - \\
\hline
\end{tabular}

${ }^{1} \mathrm{RI}=$ presumably recently infected; PSI = presumably past steadily infected; FREE $=$ presumably free of infection; $\mathrm{O}-\mathrm{Y}=$ with an outbreak; O-N = without any outbreak; RI-Y = presumably recently infected with an outbreak; RI-N = presumably recently infected without any outbreak; PSI-Y = presumably past steadily infected with an outbreak; PSI-N = presumably past steadily infected without any outbreak.

${ }^{2}$ See main text for definition. 


\section{DISCUSSION}

This study identified losses in performance associated with BRSV infection, whereas our estimates regarding BCV-infected herds were either not significantly different from those in noninfected herds or contrary in direction to biological expectations.

A significant reduction in milk yield was observed for cows in presumably BRSV RI herds, as well as in presumably BRSV O-Y herds compared with cows in presumably infection-free herds (FREE and O-N herds, respectively). In addition, there was a further significant detrimental effect in presumably RI herds when they experienced an outbreak (Table 3). These results are in accordance in direction with those reported by Norström et al. (2001) in case of a declared outbreak, but the magnitude of the decrease observed here (on average, a $0.9 \mathrm{~kg} / \mathrm{d}$ reduction over a 7 -mo period) was much higher than that in the latter study $(0.7 \mathrm{~kg} / \mathrm{d}$ over a 1-wk period). However, Norström et al. (2001) hypothesized that their result could be largely underestimated; their estimate was similar to the one reported by Van der Poel et al. (1995) in case of BRSV reinfections. Information about the relative proportion of primary infected and reinfected cows (assumed to be severely affected and to have a smaller loss in milk yield, respectively) in the affected herds was lacking in their study. The results of our study could also support their assumption, as the milk yield of cows in presumably past steadily infected herds (comprising either pastinfected cows or to some extent reinfected cows) was not different from that in presumably FREE herds.

The risk of reproductive failure after first service (Table 4) as well as risk of death in calves and heifers (Table 5) was found to be increased in herds with a presumably BRSV-related outbreak, for the former, and in presumably recently or past-infected herds, for the latter. These findings were in agreement with biological expectations and with the literature. The mortality rate can reach $20 \%$ in some severe outbreaks (Stott et al., 1980), and pneumonia and cough are recognized as major risk factors for death early in life (Waltner-Toews et al., 1986; Curtis et al., 1988; van der Fels-Klerx et al., 2002; Svensson et al., 2006). These estimates were, however, not significantly different from unity, possibly because of a lack of statistical power because of the relatively low sample sizes $(2,716$ cows with a first AI within the periods-at-risk and 4,104 calves and heifers at risk of mortality, respectively). Further studies are needed to confirm or reject the trends observed here. We also observed a significant increase in SCC (of more than 10,000 cells $/ \mathrm{mL}$ ) for cows in herds with a BRSV outbreak. This increase cannot only be caused by a concentration effect, because the increase would have been about 3,000 cells $/ \mathrm{mL}$ if exclusively in relation to the associated reduction in milk yield $(-0.91 \mathrm{~kg} / \mathrm{d})$ observed in the same herds.

The present study showed that, regardless of the performance under study, the point estimates of effects associated with BRSV infection were large in magnitude, despite the fact that they were calculated based on animal performance in the whole period-at-risk (7 mo duration). This finding, which was not expected because the BRSV infection was previously found to have only a temporary effect (Norström et al., 2001), suggests that the effect of this infection may be very severe at the time of its occurrence.

It should be discussed, however, whether the losses in productivity estimated in this study could be regarded as a direct consequence of the BRSV infection only, because causal relationships cannot easily be established in observational studies such as this. One possibility is that the increase in SCC, the higher risk of failure after first service, and higher risk of mortality of young stock are markers of poor hygiene and management. Poorly managed herds might also lack biosecurity and are therefore more likely to get infectious diseases. However, all herds under study were free from bovine viral diarrhea virus, bovine paratuberculosis, and infectious bovine rhinotracheitis.

The same question could be raised regarding $\mathrm{BCV}$ infection. However, the present study provided either nonsignificant estimates (e.g., for milk yield and SCC) or significant estimates that were contrary in direction to biological hypotheses and knowledge (e.g., lower risk of young stock death in presumably RI and in herds with a presumably BCV-related clinical outbreak; Table 5).

Two explanations could be put forth for the absence of any observed decrease in milk yield associated with BCV, although a decrease could be expected from farmers' experiences as well as from description of BCV-related outbreaks in the literature. First, the decreased milk yield associated with winter dysentery, even if large in magnitude (on average $22 \%$ ), is often described as being of short duration $(<2$ wk; Tråvén, 2000). Therefore, if it exists, such an effect would have been difficult to detect using test-day records, which are usually performed 1 mo apart. Second, the TDMY used for comparisons were all those within the periodat-risk (i.e., from October year $n$ to April year $n+1$ ), whereas winter is known to be a predisposing factor for BCV outbreaks (Saif, 1990). Thus, this strategy may have "smoothed" the possible decrease in milk yield associated with an outbreak over the whole period-atrisk. However, no precise (and reliable) information on actual dates of possible outbreaks were available and 
a more detailed analysis could therefore not be performed.

This second explanation may be less likely, because the milk yield in presumably RI-N herds was found to be significantly lower than in RI-Y (Table 2). Because both these groups experienced a recent BCV circulation, this finding might suggest that herds in which the owner noticed a presumably BCV-related clinical outbreak are better managed to some extent with higher performance. This hypothesis is also supported by the fact that only 3 of the 28 herds with a presumably BCV-related clinical outbreak also had a presumably BRSV-related clinical outbreak (for which a decrease in milk yield was observed; Table 1). In addition, it may be questioned if all outbreaks classified as BCV related were indeed related to $\mathrm{BCV}$ infection, because signs of diarrhea (the main criterion to define an outbreak) may well be related to other factors; for instance, related to feeding regimens, especially in high-performing herds where cows are more sensitive. This reason for misclassification was deemed not differential between herds exhibiting or not exhibiting specific antibodies to $\mathrm{BCV}$, because the farmers were not aware of the status of their herd when they declared the observed clinical signs. In that context, the presumably BCVrelated outbreaks might have been overestimated in our study. The same may not necessarily apply for cough, for which the risk of misclassification toward BRSV infection was deemed lower.

The assumption of better management and performance in herds with a presumably BCV-related outbreak could also indirectly explain, at least partially, the trend toward a lower risk of death in young stock in such herds (Table 5). This might also be a reason why, contrary to our expectations, $\mathrm{BCV}$ outbreaks were not found to be associated with increased SCC; the higher level of management might prevent the higher risk for a cow with diarrhea to be exposed to pathogens likely to infect the udder.

According to this study, BRSV infection had a large significant effect on milk yield and SCC and to some extent on reproduction performance of cows and survival of young stock. However, for the latter, the relationships found here should be confirmed in a larger study. The quantitative estimates of production effects associated with this infection will be useful information to assess its economic impact, as well as the profitability of control schemes that could be implemented on farms. In contrast, BCV infection, identified here based on either the dynamics of BCV-specific antibody levels over time or the occurrence of a presumably related outbreak, was not significantly associated with any production losses in cows from the infected herds com- pared with those in the FREE herds. These findings were unexpected because severe decrease in milk yield in cows with winter dysentery, as well as increased calf mortality, were identified in previous descriptions of outbreaks. Because the consequences on performances associated with BCV-related outbreaks are probably of short duration in most situations, case-control investigations relying on very reliable identification and dating of the BCV-related outbreak and of the corresponding period-at-risk, and targeting daily performance records would be a profitable area of research.

\section{ACKNOWLEDGMENTS}

The authors acknowledge Stefan Alenius and Madeleine Tråvén (both of Department of Clinical Sciences, Swedish University of Agricultural Sciences, Uppsala, Sweden) for fruitful discussions, as well as the participating farmers.

\section{REFERENCES}

Alenius, S., R. Niskanen, N. Juntti, and B. Larsson. 1991. Bovine coronavirus as the causative agent of winter dysentery: Serological evidence. Acta Vet. Scand. 32:163-170.

Beaudeau, F., and C. Fourichon. 1998. Estimating relative risk of disease from outputs of logistic regression when the disease is not rare. Prev. Vet. Med. 36:243-256.

Clark, M. A. 1993. Bovine coronavirus. Br. Vet. J. 149:51-70.

Curtis, C. R., J. M. Scarlett, H. N. Erb, and M. E. White. 1988. Path model of individual-calf risk factors for calfhood morbidity and mortality in New York Holstein herds. Prev. Vet. Med. 6:43-62.

Curtis, C. R., M. E. White, and H. N. Erb. 1989. Effects of calfhood morbidity on long-term survival in New York Holstein herds. Prev. Vet. Med. 7:173-186.

Elvander, M. 1996. Severe respiratory disease in dairy cows caused by infection with bovine respiratory syncytial virus. Vet. Rec. 3:101-105.

Elvander, M., S. Edwards, K. Näslund, and N. Linde. 1995. Evaluation and application of an indirect ELISA for the detection of antibodies to bovine respiratory syncytial virus in milk, bulk milk, and serum. J. Vet. Diagn. Invest. 7:177-182.

Emanuelson, U. 1988. The national Swedish animal disease recording system. Acta Vet. Scand. Suppl. 84:262-264.

Gröhn, Y.T., J. J. McDermott, Y. H. Schukken, J. A. Hertl, and S. W. Eicker. 1999. Analysis of correlated continuous repeated observations: Modelling the effect of ketosis on milk yield in dairy cows. Prev. Vet. Med. 39:137-153.

Hägglund, S., C. Svensson, U. Emanuelson, J. F. Valarcher, and S. Alenius. 2006. Dynamics of virus infections involved in the bovine respiratory disease complex in Swedish dairy herds. Vet. J. 172:320-328.

Harrison, L.R., and A.R. Pursell. 1985. An epizootic of respiratory syncytial virus infection in a dairy herd. J. Am. Vet. Med. Assoc. 187:716-720.

Lindberg, A. L. E., and S. Alenius. 1999. Principles for eradication of bovine viral diarrhoea virus (BVDV) infections in cattle populations. Vet. Microbiol. 64:197-222.

McNulty, M. S., D. G. Bryson, G. M. Allan, and E. F. Logan. 1984. Coronavirus in the respiratory tract. Vet. Microbiol. 9:425-434.

Norström, M., V. Edge, and J. Jarp. 2001. The effect of an outbreak of respiratory disease on herd-level milk production of Norwegian dairy farms. Prev. Vet. Med. 51:259-268. 
Odegaard, O. A., and J. Krogsrud. 1977. A field outbreak caused by bovine respiratory syncytial virus. Acta Vet. Scand. 18:429-443.

Ohlson, A., U. Emanuelson, M. Tråvén, and S. Alenius. 2009. The relationship between pooled and individual milk samples for detecting antibodies to Bovine Coronavirus and Bovine Respiratory Syncytial Virus. Page 279 in Proceedings of the International Symposium on Veterinary Epidemiology and Economics (ISVEE XII), Durban, South Africa.

Olsson, S. O., P. Baekbo, S. O. Hansson, H. Rautala, and O. Österas. 2001. Disease recording systems and herd health schemes for production diseases. Acta Vet. Scand. Suppl. 94:51-60.

Paton, D. J., K. H. Christiansen, S. Alenius, M. P. Cranwell, G. C. Pritchard, and T. W. Drew. 1998. Prevalence of antibodies to bovine virus diarrhoea virus and other viruses in bulk tank milk in England and Wales. Vet. Rec. 142:385-391.

Reynolds, D. J., J. H. Morgan, and N. Chanter. 1986. Microbiology of calf diarrhoea in southern Britain. Vet. Rec. 119:34-39.

Saif, L. J. 1990. A review of evidence implicating bovine coronavirus in the etiology of winter dysentery in cows: An enigma resolved? Cornell Vet. 80:303-311.

Saif, L. J., D. R. Redman, and K. V. Brock. 1988. Winter dysentery in adult dairy cattle: Detection of coronavirus in the faeces. Vet. Rec. 123:300-301.

Stair, E. L., M. B. Rhodes, R. G. White, and C. A. Mebus. 1972. Neonatal calf diarrhoea: Purification and electron microscopy of a coronavirus-like agent. Am. J. Vet. Res. 33:1147-1156.

Stott, E. J., L. H. Thomas, A. P. Collins, S. Crouch, J. Jebbett, G. S. Smith, P. D. Luther, and R. Caswell. 1980. A survey of virus infections of the respiratory tract of cattle and their association with disease. J. Hyg. (Lond.) 85:257-270.

Svensson, C., A. Linder, and S.-O. Olsson. 2006. Mortality in Swedish dairy calves and replacement heifers. J. Dairy Sci. 89:47694777.

Tråvén, M. 2000. Winter dysentery caused by bovine coronavirus: No rule without an exception: Diagnostics, clinical picture, epidemiology and herd immunity. PhD thesis. The Swedish Agricultural University of Agricultural Sciences, Uppsala, Sweden.

Tråvén, M., L. Björnerot, and B. Larsson. 1999. Nationwide survey of antibodies to bovine coronavirus in bulk milk from Swedish dairy herds. Vet. Rec. 14:527-529.
Tråven, M., K. Näslund, N. Linde, A. Silván, C. Fossum, K. O. Hedlund, and B. Larsson. 2001. Experimental reproduction of winter dysentery in lactating cows using BCV-comparison with BCV infection in milk-fed calves. Vet. Microbiol. 81:127-151.

Valarcher, J. F., and G. Taylor. 2007. Bovine respiratory syncytial virus infection. Vet. Res. 38:153-180.

van der Fels-Klerx, H. J., H. W. Saatkamp, J. Verhoeff, and A. A. Dijkhuizen. 2002. Effects of bovine respiratory disease on the productivity of dairy heifers quantified by experts. Livest. Prod. Sci. 75:157-166.

Van der Poel, W. H. M., M. C. M. Mourits, M. Nielen, K. Frankena, J. T. Van Oirschot, and Y. H. Schukken. 1995. Bovine respiratory syncytial virus reinfections and milk yield drops in dairy cattle. Vet. Q. 17:77-81.

Verhoeff, J., M. Van der Ban, and A. P. Van Nieuwstadt. 1984. Bovine respiratory syncytial virus infections in young dairy cattle: Clinical and hematological findings. Vet. Rec. 114:9-12.

Virtala, A. M., G. D. Mechor, Y. T. Gröhn, and H. N. Erb. 1996. The effect of calfhood diseases on growth of female dairy calves during the first 3 months of life. J. Dairy Sci. 79:1040-1049.

Waltner-Toews, D., S. W. Martin, and A. H. Meek. 1986. The effect of early calfhood health status on survivorship and age at first calving. Can. J. Vet. Res. 50:314-317.

Warnick, L. D., H. N. Erb, and M. E. White. 1994. The association of calfhood morbidity with first-lactation calving age and dystocia in New York Holstein herds. Kenya Vet. 18:177-179.

Warnick, L. D., H. N. Erb, and M. E. White. 1997. The relationship of calfjood morbidity with survival after calving in 25 New York Holstein herds. Prev. Vet. Med. 31:263-273.

Wei, L. J., D. Y. Lin, and L. Weissfeld. 1989. Regression analysis of multivariate incomplete failure time data by using the marginal distributions. J. Am. Stat. Assoc. 84:1065-1073.

White, M. E., Y. H. Schukken, and B. Tanksley. 1989. Space-time clustering of, and risk factors for, farmer-diagnosed winter dysentery in dairy cattle. Can. Vet. J. 30:948-951. 